\title{
Young Children's Theory of Mind: Home Literacy Environment, Technology Usage, and Preschool Education
}

\author{
Dilek Altun \\ Correspondence: Dilek Altun, Department of Early Childhood Education, Kırşehir Ahi Evran University, Kırşehir. \\ Turkey.
}

Received: January 6, 2019

doi:10.11114/jets.v7i3.4057
Accepted: January 27, $2019 \quad$ Online Published: February 13, 2019

URL: https://doi.org/10.11114/jets.v7i3.4057

\begin{abstract}
Theory of mind (ToM) skills involve young children's mentalizing ability to be aware of their own selves and other individuals' thoughts, beliefs, desires, and intentions (mental states). The social cognition skills are essential for processing complex social relations and overcoming interpersonal difficulties in communication. Previous studies shed light on the relationship of parenting and demographics to children's ToM skills, but do not examine the associations with both home environment and preschool education experiences. The goal of the present study is to investigate children's preschool education experience, home literacy environment (HLE), and technology usage in relation to their ToM skills. Participants were 203 preschoolers and their parents. The study data were collected using a home literacy environment questionnaire (HLEQ), theory of mind scale, and a demographic information form. The findings revealed that (a) children's ToM scores are not differentiated regarding gender, excluding the diverse belief tasks, b) children's ToM performances were differentiated in favor of children who have internet access at home, c) HLE, child age, daily TV watching, household income, maternal education, preschool experience, and shared book reading explained $46 \%$ of the total variance of preschoolers' ToM scores.
\end{abstract}

Keywords: theory of mind, young children, ecological approach, home literacy environment, technology

\section{Introduction}

Theory of mind (ToM) skills involve young children's mentalizing ability to be aware of their own selves and other individuals' thoughts, beliefs, desires, and intentions (mental states) that both differentiate the self and other perspectives processing simultaneously (Schneider, Slaughter, \& Dux, 2015; Tager-Flusberg, 2007) and attribute to others mental states to anticipate and assert behavior based on those states (Premarck \& Woodruff, 1978; Leslie, 1987; Wellman \& Liu, 2004). The social cognition skills are essential for processing complex social relations, overcoming interpersonal difficulties in communication, and exchanging accomplished information between persons (Ahmed \& Miller, 2011; Bradford, Jentzsch, \& Gomez, 2015; Kidd \& Castano, 2013). Research has shown that ToM skills are acquired during early childhood in normally developing children (Wellman, Cross, \& Watson, 2001; Wimmer \& Perner, 1983); however, children's pervasive developmental disorders, especially Autism Spectrum Disorders (ASD), showed lower performance among these tasks (Biçer \& Sarı, 2017; Leppanen, Sedgewick, Treasure, \& Tchanturia, 2018; Özen, 2011; Peterson, Slaughter, Moore, \& Wellman, 2016; Volkmar, Lord, Bailey, Schultz, \& Klin, 2004). Therefore, it is one of the important indicators of socio-cognitive development, and young children's ToM development is investigated through a wide scope of interdisciplinary research by neuroscientists, developmental psychologists, and educators alike (Corbetta, Patel, \& Shulman, 2008; Karakelle \& Ertuğrul, 2012; Ruffman, Slade, \& Crowe, 2002; Sari \& Altun, 2018; Shaw, Bryant, Malle, Povinelli, \& Pruett, 2017).

Neuro-imagining studies revealed evidence of neural bases of ToM tasks. Significant neurol activations occur in the brain during ToM task conditioning, such as in the paracingulate cortex (Gallagher, Happé, Brunswick, Fletcher, Frith, \& Frith, 2000) and posterior cingulate cortex (Fletcher, Happe, Frith, Baker, Dolan, Frackowiak, \& Frith, 1995). A meta-analysis and longitudinal research sought to identify the triggering experiences of the neural networks and developmental improvements in ToM during early childhood (Carr, Slade, Yuill, Sullivan, \& Ruffman, 2018; Foote \& Holmes-Lonergan, 2003; Slaughter, Imuta, Peterson, \& Henry, 2015; Wellman et al., 2001). Studies demonstrated that children's ToM performance increases with age (Ensor, Devine, Marks, \& Hughes, 2014; Hughes, Ensor, \& Marks, 2011; Wellman \& Liu, 2004). The majority of children who are roughly three years old (80\%) fail to pass false-belief tasks and roughly half of the developmentally shifting four-year-old children pass the task (Wellman et al., 2001). 
Furthermore, studies consistently revealed that mothers' mental states when talking with children (Carr et al., 2018; Devine \& Hughes, 2016; Ensor et al., 2014; Ruffmann, Slade, Devitt, \& Crowe, 2006), their education level (Meins, Fernyhough, Wainwright, Das Gupta, Fradley, \& Tuckey, 2002; Pears \& Moses, 2003), children's language skills (Cutting \& Dunn, 1999; Meins et al., 2002), and "pretend" play engagements (Hughes \& Dunn, 1998; Youngblade \& Dunn, 1995) are associated with children's ToM performances.

On the other hand, recent cross-cultural studies have yielded that there exists a universal developmental order in acquiring the ToM tasks; however, there is additionally a variation concerning acquisition in task orders between western (individualistic) and eastern (collectivist) societies. Children who are raised in western societies, such as Germany, Australia, and the United States, acquire the ToM skills: diverse desires (DD), diverse beliefs (DB), knowledge access (KA), false beliefs (FB), and hidden emotions (HE) sequence (Kristen, Thoermer, Hofer, Aschersleben, \& Sodian, 2006; Shahaeian, Peterson, Slaughter, \& Wellman, 2011; Wellman, Fang, \& Peterson, 2011). Children from eastern societies, such as China, Iran, and Turkey, acquire KA, wherein they comprehend that an individual who sees something knows about it, prior to comprehending DB, wherein individuals can have different beliefs regarding the same thing (Selcuk, Brink, Ekerim, \& Wellman, 2018; Shahaeian et al., 2011; Wellman, Fang, Liu, $\mathrm{Zhu}, \& \mathrm{Liu}, 2006)$. These findings revealed that cultural and parental characteristics as environmental factors are related to children's ToM development. Much of the aforementioned research in this scope has been concerned with children's ToM skills regarding demographic variables such as income, education level, number of siblings, and mothers' mental states while conversing with children. These studies shed light on the relationship of parenting and demographics to children's ToM skills, but do not examine the associations with both home and preschool experiences. In addition, a limited number of studies sought to examine the role of media exposure in young children's ToM skills (Mar, Tackett, \& Moore, 2010). Therefore, the present study attempts to elucidate young children's ToM by investigating home literacy environment, technology usage, and preschool education experience through an ecological system perspective.

\subsection{Home Literacy Environment}

Bronfenbrenner (1986) proposed an ecological system model to explain that environmental factors have an impact on human development. He articulated four complex, nested environmental systems from their inner to external microsystems, mesosystems, exosystems, and macrosystems. According to the model, the microsystem-which includes family, neighborhood, school, and friends - is the first closed environment children face (Bronfenbrenner, 1994; Bronfenbrenner \& Morris, 1998). The physical and social characteristics of the microsystem as well as the bidirectional interaction between a child and the microsystem influence his/her development and learning (Shonkoff \& Phillips, 2000). Brain studies also provide empirical neuro-imaging evidence that enriched visual, aural, and social stimulus augment synaptic pathways during early childhood (Black et al., 2017; Ducharme et al., 2016; Thompson \& Nelson, 2001). Thus, children's early experiences at home along with the physical and social characteristics of the home environment are important research foci. In order to elicit the multidimensional effect of the home environment, the home literacy environment (HLE) framework (Doiron \& Shapiro, 1988; Payne, Whitehurst, \& Angell, 1994; Shapiro, 1994) emerged. HLE is an index measuring the quality and quantity of children's materials, opportunities, parent-child shared activities, and social interactions occurring at home with parents/caregivers (Burgess, Hect, \& Lonigan, 2002; Tabors, Roach, \& Snow, 2001). The bulk of research revealed that there is a linkage between children's HLE and language development in terms of vocabulary, phonological awareness, and concepts involving print (Altun, Tantekin-Erden, \& Snow, 2018; Boerma, Mol, \& Jolles, 2017; Liu, Georgiou, \& Manolitsis, 2018; Rose, Lehrl, Ebert, \& Weinert, 2018). These results lend support for possible associations between children's ToM, and the motivation of the current study is to investigate HLE and understand the big picture of the children's ToM development rather than focus on, income, education level, number of siblings, or dialogue measuring maternal mental state. A growing body of research has indicated that there exists a significant relationship between children's story comprehension and ToM performance (Adrian, Clemente, Villanueva, \& Rieffe, 2005; Pelletier \& Beatty, 2015; Sar1 \& Altun, 2018). Furthermore, Kidd and Castano (2013) found that reading fictional stories fosters ToM skills in adults. Thus, it is possible for children's story reading experiences to bolster their ToM skills because stories provide various protagonists' perspectives along the same plot. Similarly, Mar, Tackett, and Moore (2010) found that children's movie and storybook exposure is related to their ToM skills, while television is not. However, there is a research gap in the exposure role of children information communication technologies (ICTs) on ToM development and the present study attempts to examine children's home literacy experiences and technology usage in relation to their ToM skills.

\subsection{Preschool Education}

In the microsystem, preschool represents an important socialization agent for children. Preschool education's contribution to children's whole development is a thoroughly documented issue (Bakken, Brown, \& Downing, 2017; Erkan \& Kirca, 2010; Lehrl, Kluczniok, \& Rossbach, 2016; Pianta, Barnett, Burchinal, \& Thornburg, 2009; Taner \& Başal, 2005). In addition to this formal learning experience, children spend time with their peers in the classroom 
context, and young children face conflict with peers as siblings and their teachers' conflict management and explanations may support their gaining awareness of both themselves and the perspectives of others (Blunk, Russell, \& Armga, 2017; Downer, Williford, Bulotsky-Shearer, Vitiello, Bouza, Reilly, \& Lhospital, 2018). In addition, teachers' mental state discussions and classroom story reading experiences can improve children's ToM skills (Bal \& Veltkamp, 2013; Djikic, Oatley, \& Moldoveanu, 2013; Mar, Oatley, \& Peterson, 2009). Considering the potential role of preschool education in children's ToM development, the goal of the present study is to investigate children's preschool education experience, HLE, and technology usage in relation to their ToM skills. The study seeks to answer the following research questions.

1) Is there a significant difference in preschoolers' ToM scores in regard to gender?

2) Is there a significant difference in preschoolers' HLE scores in regard to household income?

3) Is there a significant difference in preschoolers' HLE scores in regard to parental education level?

4) Is there a significant difference in preschoolers' HLE scores in regard to internet access at home?

5) Is there a significant difference in preschoolers' HLE scores in regard to the amount of preschool education experience?

6) How much variance in children's ToM scores can be explained by HLE, technology usage, and preschool education experience?

\section{Method}

The study was conducted using a correlational research design, which explores relations between the study variables without manipulating the variables in order to describe the degree of the existing relations and to determine predictive relations between variables (Creswell, 2015; McMillan, 2016).

\subsection{Participants}

Participants were 203 preschoolers (103 girls and 100 boys) and their parents (168 mothers and 35 fathers). The participating children were recruited from 15 classrooms from five public preschools in Kirşehir, Turkey using convenience sampling. The preschoolers ranged in age from 56-73 months $(\mathrm{M}=60.3, \mathrm{SD}=4.97)$. All of the children were monolingual Turkish speakers and typically developing based on their parents' and classroom teachers' reports. Detailed information regarding the participants is presented in Table 1.

Table 1. Demographic Information of the Participants

\begin{tabular}{lcc}
\hline Child's Gender & $f$ & $\mathbf{\%}$ \\
\hline Girl & 103 & 50.70 \\
Boy & 100 & 49.30 \\
\hline Household Income* & & \\
$0-1.500$ TRY & 29 & 14,30 \\
$1.501-3.000$ TRY & 59 & 29,10 \\
$3.001-4.500$ TRY & 45 & 22,20 \\
$4.501-6.000$ TRY & 29 & 14,30 \\
$6.001+$ TRY & 41 & 20,20 \\
\hline Number of Siblings & & \\
0 & 48 & 23.60 \\
1 & 115 & 56.70 \\
2 & 40 & 19.7 \\
$3+$ & 0 & 0 \\
\hline Computer Ownership at Home & & \\
Yes & 124 & 61.1 \\
No & 79 & 38.9 \\
\hline Internet Access at Home & & \\
Yes & 130 & 64 \\
No & 73 & 36 \\
\hline
\end{tabular}

The participating mothers were aged $22-50(\mathrm{M}=32.55, \mathrm{SD}=4.90)$; the fathers were aged 25-56 $(\mathrm{M}=36.29$, $\mathrm{SD}=5.11$ ). As shown in Table 2, 39.9\% of the mothers and 38.4\% of the fathers had graduated from high school. Among the parents, $27.1 \%$ of the mothers and $29.6 \%$ of the fathers had graduated from university. 
Table 2. Parents' Education Level

\begin{tabular}{lcccc}
\hline & \multicolumn{2}{c}{ Mothers } & \multicolumn{2}{c}{ Fathers } \\
Education Level & $f$ & $\%$ & $f$ & $\%$ \\
\hline Primary school & 17 & 8.4 & 9 & 4,4 \\
Middle school & 21 & 10.3 & 20 & 9,9 \\
High school & 81 & 39.9 & 78 & 38,4 \\
Associate degree* & 23 & 11.3 & 22 & 10,8 \\
University** & 55 & 27.1 & 60 & 29,6 \\
Postgraduate & 6 & 3.0 & 14 & 6,9 \\
Total & 203 & 100,0 & 203 & 100,0 \\
*Undergraduate programs lasting two years; **Undergraduate programs lasting four years
\end{tabular}

\subsection{Instruments}

The study data were collected using a home literacy environment questionnaire (HLEQ), theory of mind scale, and a demographic information form.

\subsubsection{Home Literacy Environment Questionnaire}

Marjanovic Umek, Podlesek, and Fekonja (2005) developed the questionnaire to assess young children's home literacy experiences and sources. Altun (2013) translated the HLEQ into Turkish. The questionnaire comprises 32 items on a 6-point Likert-type scale with a five-factor structure: a) stimulation to use language and explanation; b) reading books to the child, visiting the library, and puppet theatre; c) joint activities and conversation; d) interactive reading; and e) zone-of-proximal-development stimulation; the questionnaire gave a total variance of 54.1. The Cronbach's alpha value was .91 for original version. The pilot study was conducted with 754 Turkish parents, producing a Cronbach's alpha value of .89. The explained total variance by five factors was 48.7 for Turkish adaptation.

\subsubsection{The Demographic Information Form}

The demographic information form was established to collect information from parents regarding their educational level, age, household income, ICTs ownership, children's daily ICT usage time, weekly parent-child shared reading activity time, number of books at home, children's preschool education experience, and children's number of siblings.

\subsubsection{Theory of Mind Scale}

Wellman and Liu (2004) created tasks to test young children's theory of mind (ToM) skills. Gözün-Kahraman (2012) translated the tasks into Turkish. The tasks are presented to children through scenarios and materials (toys, pictures, etc.) and ordered from easy to difficult in the battery. The tasks scored 1 point for each correct answer and 0 points for each wrong answer. The Turkish version of the ToM battery was administered to 106 children aged 4-6 years. Gözün-Kahraman found the test-retest reliability was .78. Detailed information regarding the ToM tasks is presented in Table 3.

Table 3. ToM Tasks and Brief Content Description

\begin{tabular}{ll}
\hline Task Name & Content \\
\hline Diverse desire & $\begin{array}{l}\text { The child is introduced to a toy figure (Mr. Ali); then, the child is required to judge the } \\
\text { child's and Ali's different desires about eating preference (a carrot vs. a cookie). }\end{array}$ \\
\hline Diverse beliefs & $\begin{array}{l}\text { The child is introduced to a toy figure (Miss Ayşe) and then is required to judge the } \\
\text { child's and Ayşe's different beliefs about where Ayşe's cat is hiding (in the garage vs. } \\
\text { the bushes). }\end{array}$ \\
\hline Knowledge access & $\begin{array}{l}\text { The child is presented with a small box. The child is asked to predict what is in the } \\
\text { box; then, the child sees that there is a small toy dog in the box. The child is introduced } \\
\text { to another person (Zeynep) who has never seen inside of the box. The child is asked, } \\
\text { "Does Zeynep know what's in the box?" }\end{array}$ \\
\hline $\begin{array}{l}\text { Contents false } \\
\text { beliefs }\end{array}$ & $\begin{array}{l}\text { The child is presented with a Band-Aid box and asked to predict what is in the box. } \\
\text { The child sees that there is small toy horse in the box. Another person (Ahmet) is then } \\
\text { introduced; he has never seen inside the box. The child is then asked the following } \\
\text { target questions: "What does Ahmet think is inside the box? A Band-Aid or a horse? } \\
\text { Did Ahmet see the inside of this box?" }\end{array}$ \\
\hline $\begin{array}{l}\text { Real apparent } \\
\text { emotion }\end{array}$ & $\begin{array}{l}\text { The child is exposed to a short story about a boy (Mehmet). The child is required to } \\
\text { judge Mehmet's real emotions and discuss the different emotions Mehmet feels about } \\
\text { his friends' behavior toward him. }\end{array}$ \\
\hline
\end{tabular}




\subsubsection{Data Collection Procedures}

After obtaining official permission from the university ethics committee and the Ministry of National Education, 280 consent forms and HLEQs were distributed to parents via 15 preschool teachers. A total of 203 parents (72.5\%) signed the consent form and filled out the HLEQ. The ToM battery was administered to the children one-by-one in an empty classroom or room in their school. The duration of the ToM battery ranged from 10-27 minutes.

\section{Results}

Table 4 presents the data set of the study. The normal distribution of the scores was checked based on the skewness and kurtosis values and histograms. The skewness and kurtosis values of the scores did not exceed the -2 to +2 range, and the histogram graphs visually supported normal distribution. Thus, the data set has not violated normal distribution (Tabachnick \& Fidell, 2007).

Table 4. Characteristics of the Data Set

\begin{tabular}{lccccccc}
\hline & $N$ & Min & Max & $M$ & SD & Skewness & Kurtosis \\
\hline HLEQ & 203 & 75,00 & 189,00 & 146,18 & 20,87 &,- 773 &, 794 \\
ToM & 203 & 1,00 & 5,00 & 3,12 & 1,13 &,- 142 &,- 656 \\
Child age & 203 & 48,00 & 75,60 & 59,23 & 6,07 &,- 014 &, 094 \\
Daily ICTs using* & 203 & 0 & 80 & 33,97 & 12,25 & 1,822 & $1-, 777$ \\
Weekly shared book reading* & 203 & 0 & 50 & 20,83 & 9,25 & 1,494 & $1-, 835$ \\
Number of books at home & 203 & 0 & 120,00 & 56,40 & 47,56 & 1,249 & 1,604 \\
Daily TV watching* & 203 & 0 & 120.00 & 50,89 & 38,90 &, 662 &, 426 \\
\hline
\end{tabular}

*Minutes

\subsection{Preschoolers' ToM Scores Regarding Gender}

The percentages of preschoolers who passed each of the ToM tasks are included in Table 5. The study found that the majority of the children (79\%) passed the diverse desire task, whereas the minority of the children $(36.80 \%)$ passed the real apparent emotion task

Table 5. Percentages of Preschoolers' Who Passed ToM Tasks

\begin{tabular}{lll}
\hline ToM Task & $N$ & $\%$ \\
\hline Diverse desire & 203 & 79.00 \\
Diverse beliefs & 203 & 61.00 \\
Knowledge access & 203 & 72.00 \\
Contents false beliefs & 203 & 50.70 \\
Real apparent emotion & 203 & 36.80 \\
\hline
\end{tabular}

Independent sample t-tests were performed to compare preschoolers' ToM scores regarding gender. There was NOT a significant difference between girls $(\mathrm{M}=3.18, \mathrm{SD}=1.17)$ and boys $(\mathrm{M}=3.06, \mathrm{SD}=1.09)$ and the children's total ToM scores $(t[201]=.781, p>0.05)$. However, there were significant gender differences in the diverse beliefs task scores in favor of the girls $(t[201]=2.210, p<0.05)$.

\subsection{Preschoolers' ToM Scores Regarding Household Income}

One-way ANOVA analyses were carried out to compare preschoolers' ToM scores regarding household income. The test results revealed a statistically significant difference in ToM scores $(F[4,198]=7.905, p<0.05)$ with regard to income.

Table 6. One Way ANOVA results for preschoolers' ToM scores in terms of income

\begin{tabular}{lccc}
\hline Income & $N$ & $M$ & $S D$ \\
\hline $0-1.500$ TRY $^{*}$ & 29 & 2.13 & 1.21 \\
$1.501-3.000$ TRY & 59 & 3.23 & 1.03 \\
$3.001-4.500$ TRY & 45 & 3.24 & 1.13 \\
$4.501-6.000$ TRY & 29 & 3.13 & 1.12 \\
6.001+ TRY & 41 & 3.51 & .84 \\
Total & 203 & 3.12 & 1.13 \\
\hline
\end{tabular}

**According to the Ministry of Labor, Social Services, and Family (2018), the net minimum wage in Turkey is 1,603 
Turkish lira (TRY), the individual poverty threshold is set at 2.136 TRY and a living wage for a four-person family is 5.662 TRY (Confederation of Turkish Trade Unions, 2018).

The Scheffe test for post hoc comparisons was performed in order to examine where the differences in scores occurred. The results showed statistical differences among Group $1(M=2.13, S D=1.21)$ and Group $2(M=3.23, S D=1.03)$, Group $3(M=3.24, S D=1.13)$, Group $4(M=3.13, S D=1.12)$, and Group $5(M=3.51, S D=.84)$. The mean plot of the groups' ToM scores is presented in Appendix A.

\subsection{Preschoolers' ToM Scores Regarding Parental Educational Level}

One-way ANOVA analyses were carried out to compare preschoolers' ToM scores in terms of maternal education level. Levene's test was .08; thus, the data set met the homogeneity of variance. As seen in Table 7, the results imply that preschoolers' ToM scores were differentiated to a statistically significant level regarding maternal education design $(F$ $[5,197]=6.660, p<0.05)$.

Table 7. One-Way ANOVA Results for Preschoolers' ToM Scores in Terms of Maternal Education

\begin{tabular}{lcc}
\hline Education Level & $N$ & $M$ \\
\hline 1. Primary school & 17 & 2.17 \\
2.Middle school & 21 & 2.52 \\
3. High school & 81 & 3.14 \\
4. Associate degree & 23 & 3.08 \\
5. University & 55 & 3.50 \\
6.Postgraduate & 6 & 4.16 \\
Total & 203 & 3.12 \\
\hline
\end{tabular}

The Scheffe test for post hoc comparisons was conducted to examine ToM score differences among income groups. The results showed statistical differences among Group $1(M=2.17, S D=1.33)$ and Group $3(M=3.14, S D=1.08)$ as well as Group $5(M=3.50, S D=.97)$ and Group $6(M=4.16, S D=.75)$. In addition, there were statistically significant differences between Group $2(M=2.52, S D=1.20)$ and Group $4(M=3.08, S D=.84)$. The means plot of the groups' ToM scores is displayed in Appendix B. However, the test results showed statistically significant differences in ToM scores $(F[5,197]=1.874, p>0.05)$ with regard to paternal education level.

\subsection{Preschoolers' ToM Scores Regarding Internet Access at Home}

Independent samples t-test results revealed that there was a significant difference in preschoolers' ToM scores between children who have internet access in their home $(\mathrm{M}=3.26, \mathrm{SD}=1.13)$ and those who do not $(\mathrm{M}=2.87, \mathrm{SD}=1.09, \mathrm{t}$ $[201]=2.345, p<0.05$ ).

Table 8. Independent samples t-tests results of preschoolers' ToM scores regarding internet access

\begin{tabular}{cccccc}
\hline Internet access & $\mathrm{N}$ & $\mathrm{M}$ & $\mathrm{SD}$ & $\mathrm{t}$ & $p$ \\
\hline Yes & 130 & 3.26 & 1.13 & 2.345 & 0.020 \\
No & 73 & 2.87 & 1.09 & & \\
\hline
\end{tabular}

3.5 Preschoolers' ToM Scores Regarding HLE, Technology Usage, and Preschool Education Experience

A Pearson correlation analysis was conducted to examine bivariate relations between the study variables. Preliminary analyses showed that there was no violation of the assumptions of normality and linearity. As shown Table 9, there was a moderately significant relationship between the ToM total and child age $(r=0.49, p<0.01)$, HLEQ $(r=0.46, p<$ $0.01)$, parent-child shared book reading $(r=0.41, p<0.01)$, the amount of preschool education experience $(r=0.38, p$ $<0.01)$, and maternal education level $(r=0.35, p<0.01)$.

Table 9. Pearson correlation between the study variables

\begin{tabular}{lccccccccc}
\hline & 1 & 2 & 3 & 4 & 5 & 6 & 7 & 8 & 9 \\
\hline 1. Daily internet usage & - & & & & & & & & \\
2. Number of siblings & $0.27^{* * *}$ & - & & & & & & & \\
3. HLEQ & -0.11 & $-0.16^{*}$ & - & & & & & & \\
4. Child age & 0.12 & -0.08 & $0.18^{* *}$ & - & & & & & \\
5. Daily TV watching & -0.20 & $0.26^{* *}$ & -0.06 & 0.01 & - & & & & \\
6. Income & $-0.18^{*}$ & $-0.30^{*}$ & $0.38^{* * *}$ & -0.05 & -0.11 & - & & & \\
7. Maternal education & $-0.34^{*}$ & $-0.20^{* *}$ & $0.54^{* * *}$ & 0.01 & -0.10 & $0.52^{* *}$ & - & & \\
8. Preschool education experience & 0.15 & $-0.35^{*}$ & $0.25^{* * *}$ & $0.28^{* * *}$ & -0.14 & $0.33^{* *}$ & $0.27^{* *}$ & - & \\
9. Shared book reading & $-0.24^{*}$ & 0.18 & $0.47^{* * *}$ & $0.38^{* * *}$ & $-0.25^{*}$ & $0.32^{* *}$ & $0.48^{* * *}$ & $0.38^{* * *}$ & - \\
10. ToM & $-0.19^{*}$ & $-0.20^{* *}$ & $0.46^{* *}$ & $0.49^{* * *}$ & -0.05 & $0.27^{* *}$ & $0.35^{* *}$ & $0.41^{* *}$ & $0.38^{* *}$ \\
\hline
\end{tabular}

$$
* p<.05, * * \mathrm{p}<.01
$$


Multiple regression analysis was conducted to examine how the contributions of HLE, child age, daily TV watching, household income, maternal education, preschool experience, and shared book reading can predict pre-service preschoolers' ToM scores. Preliminary analysis revealed that the data set met the assumptions of the multiple regression analysis, including sample size $(n>50+9 \mathrm{~m}, \mathrm{~m}=$ predictors numbers), multicollinearity (correlations between independent and dependent variables is above 0.30 , Tolerance $>0.10$, VIF $<10$ ), outliers (Mahalanobis distance is below 27.88), linearity, and homoscedasticity assumptions (Tabachnick \& Fidell, 2007).

The analysis results showed that the model explained $46 \%$ of the total variance of preschoolers' ToM scores. According to the standardized beta $(\beta)$ coefficients of the model, child age $(\beta=0.370, p<0.05)$ was a stronger predictor than HLE $(\beta=0.210, p<0.05)$, preschool education experience $(\beta=0.161, p<0.05)$, and weekly shared book reading $(\beta=0.137$, $p<0.05)$. Furthermore, maternal education $(\beta=0.085, p>0.05)$, income $(\beta=0.073, p>0.05)$, number of siblings $(\beta=$ $-0.050, p>0.05)$, daily internet usage $(\beta=-0.108, p>0.05)$, and daily TV watching $(\beta=0.006, p>0.05)$ were not significant predictors of the model.

Table 10. Results of multiple regression analysis for preschoolers' ToM scores

\begin{tabular}{lccccccc}
\hline & $B$ & $S E$ & $\beta$ & $t$ & $p$ & Tolerance & VIF \\
\hline (Constant) & -3.476 & 0.752 & & -4.624 & 0.000 & & \\
HLEQ & 0.011 & 0.004 & 0.210 & 2.891 & 0.004 & 0.536 & 1.866 \\
Preschool education & 0.029 & 0.011 & 0.161 & 2.765 & 0.006 & 0.825 & 1.212 \\
Maternal education & 0.074 & 0.061 & 0.085 & 1.216 & 0.226 & 0.579 & 1.728 \\
Income & 0.062 & 0.054 & 0.073 & 1.149 & 0.252 & 0.705 & 1.419 \\
Child age & 0.070 & 0.011 & 0.370 & 6.577 & 0.000 & 0.886 & 1.129 \\
Number of siblings & -0.003 & 0.004 & -0.050 & -0.809 & 0.419 & 0.722 & 1.385 \\
Daily internet usage & -0.011 & 0.006 & -0.108 & -1.766 & 0.079 & 0.757 & 1.321 \\
Daily TV watching & 0.008 & 0.072 & 0.006 & 0.109 & 0.913 & 0.859 & 1.164 \\
Weekly shared reading & 0.124 & 0.060 & 0.137 & 2.078 & 0.039 & 0.650 & 1.538 \\
\hline
\end{tabular}

$N=203, R^{2}=0.46$, corrected $R^{2}=0.45, F=18.385, p=0.000$.

\section{Discussion}

In this study, young children's ToM skills were examined regarding the home environment and preschool education experience contexts. The study's findings revealed that children's age is moderately related $(r=0.49)$ to their ToM skills. Similarly, Selcuk et al. (2018) found a significant relationship $(r=0.47)$ between children's ages and ToM skills. The developmental order in ToM skills acquisition has been addressed in previous studies (Hughes et al., 2011; Jenkins \& Astington, 1996; Miller, 2009; Wellman et al., 2001). Furthermore, the present study showed that Turkish preschoolers gain ToM skills in the sequence of DD, KA, DB, FB, RAE, similar to children in Eastern societies (Selcuk et al., 2018; Shahaeian et al., 2011; Wellman et al., 2006) but different from those in Western societies (Kristen et al., 2006; Shahaeian et al., 2011). Cultural variances between the ToM sequence of acquisition can be interpreted to reflect on parents' child rearing values, practices, social rules, and expectations in collectivist vs. individualist societies (Shahaeian et al., 2011; Wellman et al., 2006). Furthermore, these findings can be examined in the light of Vygotskian perspectives about the role of language/discourse and the mind in the cultural-historical theory of humans. Therefore, cross-cultural studies should examine parent-child discourses and mental-states usage in different cultures and their relationship to the sequence of children's ToM acquisition.

This study also revealed that preschoolers' ToM skills are not differentiated regarding gender, excluding the diverse belief tasks. In line with this finding, other studies had gender-neutral findings regarding young children's ToM abilities (Altun, 2018; Carr et al., 2018; Devine \& Hughes, 2016; Wellman \& Liu, 2004). However, the limited number of studies conducted with Turkish preschoolers (Sar1 \& Altun, 2018; Selcuk et al., 2018) found that girls outperformed the boys in ToM tasks, but also that the gender differences are more likely to be reported in older children with regard to socialization and gender roles (Calero, Salles, Semelman, \& Sigman, 2013; Devine \& Hughes, 2016).

Turning now to the results of other sub-analyses, children's ToM performances were differentiated in favor of children who have internet access at home. Although, children's daily time on online platforms and watching TV were not predictors of their ToM scores. Children who have internet access at home may be related their household income thus it was found related to their ToM scores. On the other hand, Mar et al. (2010), however, found that inferred movie and TV exposure is associated with children's ToM performances. Nathanson, Sharp, Aladé, Rasmussen and Christy (2013) 
found that children's ToM performance was negatively associated with TV exposure. However, parent-child discourse of TV watching was positively associated with children's ToM performance. Previous studies addressed that Turkish children mostly play digital games and watch cartoons on online platforms (Altun, 2017; Altun \& Tantekin-Erden, 2015). Therefore, children's technology usage, not just the time spent but also the quantity and content, as well as parent involvement in technology usage should be examined jointly as qualitative aspects to clarify media exposure's influence on ToM development.

Another finding of the present study was that preschoolers' ToM scores were differentiated in terms of maternal education level but not paternal education level. As shown throughout in the literature, maternal education level is closely related to children's ToM performance (Cutting \& Dunn, 1999; Meins et al., 2002; Pears \& Moses, 2003; Ruffman et al., 2002). Intriguingly, when maternal education was entered into multiple regression models with other variables, it was found that it is not a significant predictor of ToM. The results of this study are therefore in line with a growing body of research that has shown that maternal mental-state talking with children, child rearing practices, and family backgrounds are related to the mothers' education level (Cutting \& Dunn, 1999; Ruffman et al., 2002; Shahaeian, Henry, Razmjoee, Teymoori \& Wang, 2015; Thompson \& Nelson, 2001) and children's ToM skills. In this model, the home literacy environment and parent-child shared reading activities entered the model jointly with maternal education level, thus, maternal education may be indirectly related to ToM and directly related to mother-child interactions and HLE. The present study also found that maternal education is strongly associated $(r=0.54)$ with HLE. Similarly, children's ToM scores were statistically differentiated regarding income, but when entering it into the model with other study variables, it was not a statistically significant predictor. Correlation analysis showed that there were strong relationships between income and maternal education. In addition, there were moderate relationships between income and HLE, shared reading activities, and preschool education experience. Therefore, further studies should examine direct and indirect relationships between maternal education, income, HLE, shared reading, and preschool education experience on ToM scores by using path models.

Perhaps the most interesting contribution of this study is its examination of the home environment and preschool education experience's role in young children's ToM skills. The study findings revealed that both home and preschool education are associated with children's ToM performance. Children who have more preschool education experience and come from an enriched HLE background have higher ToM skills. As a limitation, the present study only used preschool education experience in months. Further studies should include a longer time frame as well as examine preschool education quality regarding teacher mental-state talking with children, peer relations, storybook reading experiences, and social interactions in a classroom environment with HLE by using multilevel modeling. In sum, ToM is a complex social cognition that covers the differentiated self, other perspective processing, and has the capability to predict another person's behaviors based on their mental state. Therefore, children's wide range of skills, such as language, executive functions, working memory (Carlson, Mandell, \& Williams, 2004; Duh, Paik, Miller, Gluck, Li, \& Himelfarb, 2016; Mutter, Alcorn, \& Welsh, 2006), and demographics, as well as parenting and early childhood education experiences can be related to their ToM skills. The study variables, however, can only explain only $46 \%$ of the variance in children's ToM skills. As a limitation, the present study does not address children's language skills and other cognitive skills. Future studies should investigate young children's ToM skills addressing language and other cognitive abilities to broaden our understanding of ToM development.

\section{References}

Adrian, J. E., Clemente, R. A., Villanueva, L., \& Rieffe, C. (2005). Parent-child picture-book reading, mothers' mental state language and children's theory of mind. Journal of Child Language, 32(3), 673-686. https://doi.org/10.1017/S0305000905006963

Ahmed, F. S., \& Miller, L. S. (2011). Executive function mechanisms of theory of mind. Journal of Autism and Developmental Disorders, 41, 667-678. https://doi.org/10.1007/s10803-010-1087-7

Altun, D. (2013). An investigation of the relationship between preschoolers' reading attitudes and home literacy environment (Unpublished Masters thesis). Middle East Technical University. Ankara.

Altun, D. (2017). Young children's literacy habits in digital world regarding digital equality perspective. Paper presented at the 69th OMEP World Assembly and International Conference, Opatija, Croatia.

Altun, D. (2018). Preschoolers' pro-environmental orientations and theory of mind: ecocentrism and anthropocentrism in ecological dilemmas. Early Child Development and Care, 1-13.

https://doi.org/10.1080/03004430.2018.1542385 
Altun, D., Tantekin, E. F., \& Snow, C. E. (2018). A multilevel analysis of home and classroom literacy environments in relation to preschoolers' early literacy development. Psychology in the Schools, 55(9), 1098-1120. https://doi.org/10.1002/pits.22153

Bakken, L., Brown, N., \& Downing, B. (2017). Early childhood education: The long-term benefits. Journal of research in Childhood Education, 31(2), 255-269. https://doi.org/10.1080/02568543.2016.1273285

Bal, P. M., \& Veltkamp, M. (2013). How does fiction reading influence empathy? An experimental investigation on the role of emotional transportation. PloS One, 8(1), e55341. https:// doi.org/ 10.1371/ journal. pone. 0055341

Biçer, E., \& Sari, O. T. (2017). Examination of the relationship between theory of mind and executive function skills for students with normal development and students with mild mental disabilities. Journal of Theory and Practice in Education, 13(2), 261-276. https://doi.org/10.17244/eku.310222

Black, M. M., Walker, S. P., Fernald, L. C., Andersen, C. T., DiGirolamo, A. M., Lu, C., ... Devercelli, A. E. (2017). Early childhood development coming of age: science through the life course. The Lancet, 389(10064), 77-90. https://doi.org/10.1016/S0140-6736(16)31389-7

Blunk, E. M., Russell, E. M., \& Armga, C. J. (2017). The role of teachers in peer conflict: implications for teacher reflections. Teacher Development, 21(5), 597-608. https://doi.org/10.1080/13664530.2016.1273847

Boerma, I. E., Mol, S. E., \& Jolles, J. (2017). The role of home literacy environment, mentalizing, expressive verbal ability, and print exposure in third and fourth graders' reading comprehension. Scientific Studies of Reading, 21(3), 179-193. https://doi.org/10.1080/10888438.2016.1277727

Bradford, E. E., Jentzsch, I., \& Gomez, J. C. (2015). From self to social cognition: Theory of mind mechanisms and their relation to executive functioning. Cognition, 138, 21-34. https://doi.org/10.1016/j.cognition.2015.02.001

Bronfenbrenner, U. (1986). Recent advances in research on the ecology of human development. In R. K. Silbereisen, K. Eyferth, \& G. Rudinger (Eds.), Development as action in context: Problem behavior and normal youth development (pp. 287-309). New York: Springer. https://doi.org/10.1007/978-3-662-02475-1_15

Bronfenbrenner, U. (1994). Ecological models of human development. International Encyclopedia Of Education, 3(2), $37-43$.

Bronfenbrenner, U., \& Morris, P. A. (1998). The ecology of developmental processes. In W. Damon \& R. M. Lerner (Eds.), Handbook of child psychology: Theoretical models of human development (pp. 993-1028). New York: John Wiley \& Sons.

Burgess, S. R., Hecht, S. A., \& Lonigan, C. J. (2002). Relations of the home literacy environment (HLE) to the development of reading-related abilities: A one-year longitudinal study. Reading Research Quarterly, 37(4), 408-426. https://doi.org/10.1598/RRQ.37.4.4

C). Mother and infant talk about mental states relates to desire language and emotion understanding. Child Development, $77(2), 465-481$.

Calero, C. I., Salles, A., Semelman, M., \& Sigman, M. (2013). Age and gender dependent development of theory of mind in 6-to 8-years old children. Frontiers in Human Neuroscience, 7, 281. https://doi.org/10.3389/fnhum.2013.00281

Carlson, S. M., Mandell, D. J., \& Williams, L. (2004). Executive function and theory of mind: stability and prediction from ages 2 to 3. Developmental Psychology, 40(6), 1105-1122. https://doi.org/10.1037/0012-1649.40.6.1105

Carr, A., Slade, L., Yuill, N., Sullivan, S., \& Ruffman, T. (2018). Minding the children: A longitudinal study of mental state talk, theory of mind, and behavioural adjustment from the age of 3 to 10. Social Development, 27(4), 826-840. https://doi.org/10.1111/sode.12315

Corbetta, M., Patel, G., \& Shulman, G. L. (2008). The reorienting system of the human brain: from environment to theory of mind. Neuron, 58(3), 306-324. https://doi.org/10.1016/j.neuron.2008.04.017

Creswell, J. W. (2015). Educational research: Planning, conducting, and evaluating quantitative. New Jersey: Pearson.

Cutting, A. L., \& Dunn, J. (1999). Theory of mind, emotion understanding, language, and family background: Individual differences and interrelations. Child Development, 70(4), 853-865. https://doi.org/10.1111/1467-8624.00061

Devine, R., \& Hughes, C. (2016). Family correlates of false belief understanding in early childhood: a meta-analysis. Child Development, https://doi.org/10.1111/cdev.12682

Djikic, M., Oatley, K., \& Moldoveanu, M. C. (2013). Reading other minds: Effects of literature on empathy. Scientific 
Study of Literature, 3(1), 28-47. https://doi.org/10.1075/ssol.3.1.06dji

Doiron, R., \& Shapiro, J. (1988). Home literacy environment and children's sense of story. Reading Psychology: An International Quarterly, 9(3), 187-202. https://doi.org/10.1080/0270271880090302

Downer, J. T., Williford, A. P., Bulotsky-Shearer, R. J., Vitiello, V. E., Bouza, J., Reilly, S., \& Lhospital, A. (2018). Using data-driven, video-based early childhood consultation with teachers to reduce children's challenging behaviors and improve engagement in preschool classrooms. School Mental Health, 10(3), 226-242. https://doi.org/10.1007/s12310-017-9237-0

Ducharme, S., Albaugh, M. D., Nguyen, T. V., Hudziak, J. J., Mateos-Pérez, J. M., Labbe, A., ... Brain Development Cooperative Group. (2016). Trajectories of cortical thickness maturation in normal brain development-the importance of quality control procedures. Neuroimage, 125, 267-279.

https://doi.org/10.1016/j.neuroimage.2015.10.010

Duh, S., Paik, J. H., Miller, P. H., Gluck, S. C., Li, H., \& Himelfarb, I. (2016). Theory of mind and executive function in Chinese preschool children. Developmental Psychology, 52(4), 582-591. https://doi.org/10.1037/a0040068

Ensor, R., Devine, R. T., Marks, A., \& Hughes, C. (2014). Mothers' cognitive references to 2-year-olds predict theory of mind at ages 6 and 10. Child Development, 85(3), 1222-1235. https://doi.org/10.1111/cdev.12186

Erkan, S., \& Kirca, A. (2010). A study on the effects of preschool education on primary first graders' school preparedness. (H. U. Journal of Education, 38, 94-106.

Fletcher, P. C., Happe, F., Frith, U., Baker, S. C., Dolan, R. J., Frackowiak, R. S., \& Frith, C. D. (1995). Other minds in the brain: a functional imaging study of "theory of mind" in story comprehension. Cognition, 57(2), 109-128. https://doi.org/10.1016/0010-0277(95)00692-R

Foote, R. C., \& Holmes-Lonergan, H. A. (2003). Sibling conflict and theory of mind. British Journal of Developmental Psychology, 2l(1), 45-58. https://doi.org/10.1348/026151003321164618

Gallagher, H. L., Happé, F., Brunswick, N., Fletcher, P. C., Frith, U., \& Frith, C. D. (2000). Reading the mind in cartoons and stories: an fMRI study of 'theory of mind'in verbal and nonverbal tasks. Neuropsychologia, 38(1), 11-21. https://doi.org/10.1016/S0028-3932(99)00053-6

Gözün-Kahraman, Ö. (2012). Investigation of the theory of mind based training program's effects on the 48-60 months-old children's cognitive perspective taking skills and prosocial behaviors. (Unpublished dissertation). Gazi University, Turkey.

Hughes, C., \& Dunn, J. (1998). Understanding mind and emotion: longitudinal associations with mental-state talk between young $\quad$ friends. Developmental $\quad$ Psychology, 34(5), $1026-1037$. https://doi.org/10.1037/0012-1649.34.5.1026

Hughes, C., Ensor, R., \& Marks, A. (2011). Individual differences in false belief understanding are stable from 3 to 6 years and predict children's mental state talk with school friends. Journal of Experimental Child Psychology, 108, 96-112. https://doi.org/10.1016/j.jecp.2010.07.012

Jenkins, J. M., \& Astington, J. W. (1996). Cognitive factors and family structure associated with theory of mind development in young children. Developmental Psychology, 32(1), 70-78. https://doi.org/10.1037/0012-1649.32.1.70

Karakelle, S., \& Ertugrul, Z. (2012). Do developmental relationships between theory of mind, language, working memory, and executive functions show differences across early (36-48 months) and late (53-72 months) age groups?. Turkish Journal of Psychology, 27(70), 1-25.

Kidd, D. C., \& Castano, E. (2013). Reading literary fiction improves theory of mind. Science, 342(6156), 377-380. https://doi.org/10.1126/science. 1239918

Kristen, S., Thoermer, C., Hofer, T., Aschersleben, G., \& Sodian, B. (2006). Validation of the "Theory of Mind" scale. Zeitschrift für Entwicklungspsychologie Und Paedagogische Psychologie, 38, 186-195. https://doi.org/10.1026/0049-8637.38.4.186

Lehrl, S., Kluczniok, K., \& Rossbach, H. G. (2016). Longer-term associations of preschool education: The predictive role of preschool quality for the development of mathematical skills through elementary school. Early Childhood Research Quarterly, 36, 475-488. https://doi.org/10.1016/j.ecresq.2016.01.013

Leppanen, J., Sedgewick, F., Treasure, J., \& Tchanturia, K. (2018). Differences in the Theory of Mind profiles of patients with anorexia nervosa and individuals on the autism spectrum: A meta-analytic review. Neuroscience \& 
Biobehavioral Reviews, 90, 146-163. https://doi.org/10.1016/j.neubiorev.2018.04.009

Leslie, A. M. (1987). Pretense and representation: The origins of "theory of mind." Psychological Review, 94(4), 412-426. https://doi.org/10.1037/0033-295X.94.4.412

Liu, C., Georgiou, G. K., \& Manolitsis, G. (2018). Modeling the relationships of parents' expectations, family's SES, and home literacy environment with emergent literacy skills and word reading in Chinese. Early Childhood Research Quarterly, 43, 1-10. https://doi.org/10.1016/j.ecresq.2017.11.001

Mar, R. A., Oatley, K., \& Peterson, J. B. (2009). Exploring the link between reading fiction and empathy: Ruling out individual differences and examining outcomes. Communications, 34(4), 407-428. https://doi.org/10.1515/COMM.2009.025

Mar, R. A., Tackett, J. L., \& Moore, C. (2010). Exposure to media and theory-of-mind development in preschoolers. Cognitive Development, 25(1), 69-78. https://doi.org/10.1016/j.cogdev.2009.11.002

Marjanovič Umek, L., Podlesek, A., \& Fekonja, U. (2005). Assessing the home literacy environment. European Journal of Psychological Assessment, 21(4), 271-281. https://doi.org/10.1027/1015-5759.21.4.271

McMillan, J. H. (2016). Fundamentals of educational research. Boston:Pearson.

Meins, E., Fernyhough, C., Wainwright, R., Das Gupta, M., Fradley, E., \& Tuckey, M. (2002). Maternal mindmindedness and attachment security as predictors of theory of mind understanding. Child Development, 73(6), 1715-1726. https://doi.org/10.1111/1467-8624.00501

Miller, S. A. (2009). Children's understanding of second-order mental states. Psychological Bulletin, 135(5), 749-773. https://doi.org/10.1037/a0016854

Mutter, B., Alcorn, M. B., \& Welsh, M. (2006). Theory of mind and executive function: Working-memory capacity and inhibitory control as predictors of false-belief task performance. Perceptual and Motor Skills, 102(3), 819-835. https://doi.org/10.2466/pms.102.3.819-835

Nathanson, A. I., Sharp, M. L., Aladé, F., Rasmussen, E. E., \& Christy, K. (2013). The relation between television exposure and theory of mind among preschoolers. Journal of Communication, 63(6), 1088-1108. https://doi:10.1111/jcom.12062

Özen, K. (2011). Özel öğrenme güçlüğü tanısı almış 7-9 yaş çocukların geliştirdikleri zihin kuramı yeteneklerinin sağlıklı gelişim gösteren grup ile karşılaştırılması. Hacettepe University Faculty of Health Sciences Journal, 1, 558-576. Retrieved from http://dergipark.gov.tr/download/article-file/88890

Payne, A. C., Whitehurst, G. J., \& Angell, A. L. (1994). The role of home literacy environment in the development of language ability in preschool children from low-income families. Early Childhood Research Quarterly, 9(3-4), 427-440. https://doi.org/10.1016/0885-2006(94)90018-3

Pears, K. C., \& Moses, L. J. (2003). Demographics, parenting, and theory of mind in preschool children. Social Development, 12(1), 1-20. https://doi.org/10.1111/1467-9507.00219

Pelletier, J., \& Beatty, R. (2015). Children's understanding of Aesop's fables: Relations to reading comprehension and theory of mind. Frontiers in Psychology, 6, 1448. https://doi.org/10.3389/fpsyg.2015.01448

Peterson, C., Slaughter, V., Moore, C., \& Wellman, H. M. (2016). Peer social skills and theory of mind in children with autism, deafness, or typical development. Developmental Psychology, 52(1), 46-57. https://doi.org/10.1037/a0039833

Pianta, R. C., Barnett, W. S., Burchinal, M., \& Thornburg, K. R. (2009). The effects of preschool education: What we know, how public policy is or is not aligned with the evidence base, and what we need to know. Psychological Science in the Public Interest, 10(2), 49-88. https://doi.org/10.1177/1529100610381908

Premack, D., \& Woodruff, G. (1978). Does the chimpanzee have a theory of mind? The Behavioral and Brain Sciences, 4, 515-526. https://doi.org/10.1017/S0140525X00076512

Rose, E., Lehrl, S., Ebert, S., \& Weinert, S. (2018). Long-Term Relations Between Children's Language, the Home Literacy Environment, and Socioemotional Development From Ages 3 to 8. Early Education and Development, 29(3), 342-356. https://doi.org/10.1080/10409289.2017.1409096

Ruffman, T., Slade, L., \& Crowe, E. (2002). The relation between children's and mothers' mental state language and theory-of-mind understanding. Child Development, 73(3), 734-751. https://doi.org/10.1111/1467-8624.00435

Ruffman, T., Slade, L., Devitt, K., \& Crowe, E. (2006). What mothers say and what they do: The relation between parenting, theory of mind, language and conflict/cooperation. British Journal of Developmental Psychology, 24, 
105-124. https://doi.org/10.1348/026151005X82848

Sar1, B., \& Altun, D. (2018). An examination of the relationship between preschoolers' story comprehension and theory of mind skill. Journal of Mother Tongue Education, 6(4), 945-960. https://doi.org/10.16916/aded.441307

Schneider, D., Slaughter, V. P., \& Dux, P. E. (2015). What do we know about implicit false-belief tracking? Psychonomic Bulletin \& Review, 22(1), 1-12. https://doi.org/10.3758/s13423-014-0644-z

Selcuk, B., Brink, K. A., Ekerim, M., \& Wellman, H. M. (2018). Sequence of theory-of-mind acquisition in Turkish children from diverse social backgrounds. Infant and Child Development, https://doi.org/10.1002/icd.2098

Shahaeian, A., Henry, J. D., Razmjoee, M., Teymoori, A., \& Wang, C. (2015). Towards a better understanding of the relationship between executive control and theory of mind: an intra-cultural comparison of three diverse samples. Developmental Science, 18(5), 671-685. https://doi.org/10.1111/desc.12243

Shahaeian, A., Peterson, C. C., Slaughter, V., \& Wellman, H. M. (2011). Culture and the sequence of steps in theory of mind development. Developmental Psychology, 47(5), 1239-1247. https://doi.org/10.1037/a0023899

Shapiro, J. (1994). Home literacy environment and young children's literacy knowledge and behavior. Paper presented at the Annual Meeting of the College Reading Association. Retrieved from https://files.eric.ed.gov/fulltext/ED381750.pdf

Shaw, J. A., Bryant, L. K., Malle, B. F., Povinelli, D. J., \& Pruett Jr, J. R. (2017). The relationship between joint attention and theory of mind in neurotypical adults. Consciousness and Cognition, 51, 268-278. https://doi.org/10.1016/j.concog.2017.02.012

Shonkoff, J., \& Phillips, D. A. (Eds.). (2000). From neurons to neighborhoods. Washington, DC: National Academy of Sciences.

Slaughter, V., Imuta, K., Peterson, C. C., \& Henry, J. D. (2015). Meta-analysis of theory of mind and peer popularity in the preschool and early school years. Child Development, 86(4), 1159-1174. https://doi.org/10.1111/cdev.12372

Tabachnick, B. G., \& Fidell, L. S. (2007). Using multivariate analysis. Boston: Pearson

Tabors, P. O., Roach, K. A., \& Snow, C. E. (2001). Home language and literacy environment: Final results. In D. K. Dickinson \& P. O. Tabors (Eds.), Beginning literacy with language: Young children learning at home and school (pp. 111-138). Baltimore: Paul H Brookes Publishing.

Tager-Flusberg, H. (2007). Evaluating the theory-of-mind hypothesis of autism. Current Directions in Psychological Science, 16(6), 311-315. https://doi.org/10.1111/j.1467-8721.2007.00527.x

Taner, M., \& Başal, H. A. (2005). Compare language development in first grade primary school students from different socioeconomic levels who take and do not take pre-school education according to the gender. Uludağ Üniversitesi Ë̆itim Fakültesi Dergisi, 18(2), 395-420.

Thompson, R. A., \& Nelson, C. A. (2001). Developmental science and the media: Early brain development. American Psychologist, 56(1), 5-15. https://doi.org/10.1037/0003-066X.56.1.5

Volkmar, F. R., Lord, C., Bailey, A., Schultz, R. T., \& Klin, A. (2004). Autism and pervasive developmental disorders. Journal of Child Psychology and Psychiatry, 45(1), 135-170. https://doi.org/10.1046/j.0021-9630.2003.00317.x

Wellman, H. M., \& Liu, D. (2004). Scaling of theory-of-mind tasks. Child Development, 75(2), 523-541. https://doi.org/10.1111/j.1467-8624.2004.00691.x

Wellman, H. M., Cross, D., \& Watson, J. (2001). Meta-analysis of theory-of-mind development: The truth about false belief. Child Development, 72(3), 655-684. https://doi.org/10.1111/1467-8624.00304

Wellman, H. M., Fang, F., \& Peterson, C. C. (2011). Sequential progressions in a theory-of-mind scale: Longitudinal perspectives. Child Development, 82(3), 780-792. https://doi.org/10.1111/j.1467-8624.2011.01583.x

Wellman, H. M., Fang, F., Liu, D., Zhu, L., \& Liu, G. (2006). Scaling of theory-of-mind understandings in Chinese children. Psychological Science, 17, 1075-1081. https://doi.org/10.1111/j.1467-9280.2006.01830.x

Wimmer, H., \& Perner, J. (1983). Beliefs about beliefs: Representation and constraining function of wrong beliefs in young children's understanding of deception. Cognition, 13(1), 103-128.

https://doi.org/10.1016/0010-0277(83)90004-5

Youngblade, L. M., \& Dunn, J. (1995). Individual differences in young children's pretend play with mother and sibling: Links to relationships and understanding of other people's feelings and beliefs. Child Development, 66, 1472-1492. https://doi.org/10.2307/1131658 


\section{Appendix A}

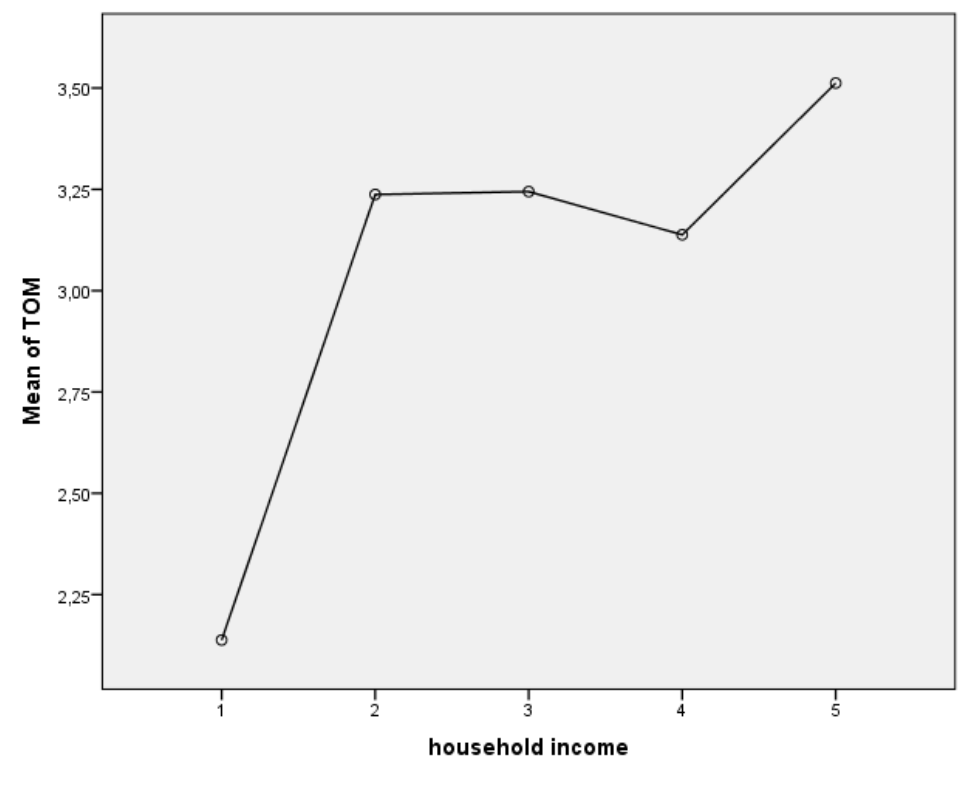

The ToM means plot of household income

\section{Appendix B}

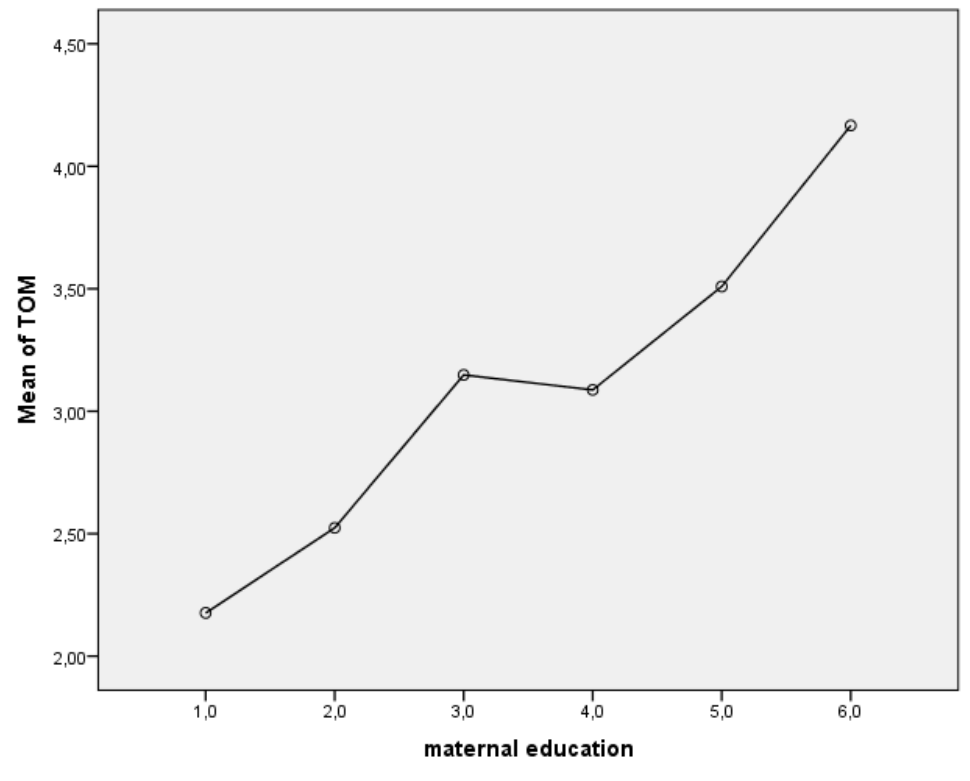

The ToM means plot of mothers' education level

\section{Copyrights}

Copyright for this article is retained by the author(s), with first publication rights granted to the journal.

This is an open-access article distributed under the terms and conditions of the Creative Commons Attribution license which permits unrestricted use, distribution, and reproduction in any medium, provided the original work is properly cited. 